\title{
Review of health risks among decontamination workers after the Fukushima Daiichi Nuclear Power Plant Accident
}

\author{
Toyoaki Sawano ${ }^{1,2,3,}$, Akihiko Ozaki ${ }^{3,4}$ and Masaharu Tsubokura ${ }^{2,3}$ \\ ${ }^{1}$ Department of Surgery, Jyoban Hospital of Tokiwa Foundation, Fukushima, Japan. \\ ${ }^{2}$ Department of Radiation Health Management, Fukushima Medical University School of Medicine, Fukushima, Japan. \\ ${ }^{3}$ Research Center for Community Health, Minamisoma Municipal General Hospital, 54-6 Takamicho 2 chome, Haramachi, Minamisoma, \\ Fukushima, Japan. \\ ${ }^{4}$ Department of Breast Surgery, Jyoban Hospital of Tokiwa Foundation, Iwaki, Fukushima, Japan.
}

Received: 22 October 2020 / Accepted: 15 November 2020

\begin{abstract}
In the radiation industry, occupational health is a significantly important issue. As the workers belong to a wide range of socioeconomic classes, the management of the health of the workers, especially in a lower socioeconomic status, such as migrant workers, is essential. After the Fukushima Daiichi Nuclear Power Plant (FDNPP) accident, migrant decontamination workers were recruited to help clean up and mitigate the ionizing radiation in evacuation zone, in order to resume life. As this was the first attempt at such decontamination work after a nuclear accident, these workers were the first to experience these conditions. However, limited information is available on the health of the workers engaged in this work. This paper comprehensively reviews the existing health risks faced by the workers after the FDNPP accident to provide general health guidelines to mitigate the health risks of decontamination workers in future disasters. Following previous literature, the health risks were categorized by those associated with occupational hazards and those associated with the living environment. Not only a mitigation of the direct occupational hazards, such as radiation exposure, work-related infection and trauma during work, but also the management of lifestyle should be adequately supported for decontamination workers of future nuclear disasters.
\end{abstract}

Keywords: occupational hazard / occupational health / non-communicable disease / socioeconomic status / radiation accident

\section{Introduction}

Occupational health is one of the growing global health issues (World Health Organization, 2011). Half of the world's population is engaged in some form of employment and face certain health risks related to that occupation. In particular, vulnerable populations, such as older individuals and those with a low socioeconomic status (SES) are more susceptible to these risks because they often have difficulty in extricating themselves from unfavorable conditions for socio-economic reasons or physical and psychological disadvantages (Bethel et al., 2011; Anikeeva et al., 2016). In order to promote the health of the workers in the radiation industry, who come from a wide range of socioeconomic backgrounds, it is important to consider specific and nuanced methods to improve their occupational safety.

Migrant workers, who migrate from their home place (within or outside their home country) to pursue work, are a

\footnotetext{
*Corresponding author: toyoakisawano@gmail.com
}

vulnerable population, both in terms of health and social status. For example, it has been suggested that migrant agricultural workers and miners are more likely to be exposed to a broad range of occupational hazards (Mobed et al., 1992; Joyce, 1998) as their low SES, which is measurable by the level of education, income, and occupation, may be associated with strenuous tasks (Singh et al., 1997; Muennig et al., 2007). Exposure to occupational hazards may exacerbate the unhealthy lifestyles and poor access to health services associated with a deficit in social and economic resources, leading to a higher mortality rate in migrant workers (Reid and Sluis-Cremer, 1996). In order to promote their health, it is imperative to pay attention to not only the prevention of direct work-related diseases and injuries, but also a more comprehensive health analysis. However, there is little information available on the health of migrant workers, as the migratory nature of their employment and lifestyle have made a detailed investigation difficult.

After the Fukushima Daiichi Nuclear Power Plant (FDNPP) accident, following the Great East Japan Earthquake and subsequent tsunami in March 2011, a wide variety of 
workers have been engaged in different types of works to mitigate the damage (Hiraoka et al., 2015; Ohtsuru et al., 2015). In the immediate aftermath of the accident, the SelfDefense Forces, firefighters, and employees of Tokyo Electric Power Company (TEPCO) and its related companies were engaged in cooling the reactor and minimizing the spread of radiation. Over the longer term, workers in decommissioning, decontamination, and interim storage facilities for radioactive waste have been working to bring the accident under control (Ohtsuru et al., 2015). The decontamination work focused on minimizing the external radiation exposure level to less than $1 \mathrm{mSv}$ per year for residents living in the affected areas, as measured after decontamination cleaning (Yasui, 2013). In general, decontamination workers handle materials with high levels of radioactivity, such as in highly contaminated areas of the plant; however, post-Fukushima decontamination workers operated in areas with lower levels of air-borne radiation in order to clean up the living areas of the evacuation areas to resume life after the nuclear accident. Many locally based workers were recruited for the decommissioning work because it will likely be a very long-term process (30-40 years); according to a report from the TEPCO, approximately $60 \%$ of the decommissioning workers were from Fukushima Prefecture. However, the decontamination work required decontaminating large areas over a relatively short span of several years, and saw an influx of workers from the construction industry, coming from outside of the affected areas as a type of migrant worker. Decontamination work is effective in minimizing the exposure of residents in areas where radioactive materials have been dispersed in a nuclear accident, and the personnel involved in this work play an important role for rehabilitation of the exclusion zone after a nuclear disaster (Tsubokura et al., 2019). Therefore, it is imperative to understand and manage their health appropriately, and previous studies have shown that the decontamination workers after the FDNPP accident have been exposed to a wide range of health risks beyond radiation exposure. While a review of the health issues among workers associated with the accident at the FDNPP has been published, limited information was available on the health of the decontamination workers at the time of this publication (Hiraoka et al., 2015).

This paper provides a comprehensive review of the existing health risks among workers engaged in decontamination works after the FDNPP accident to provide general health guidelines to mitigate the health risks of decontamination workers of future disasters.

\section{Living and working environment of decontamination workers}

At the peak of work between 2014 and 2016, 40000 50000 workers per year were recruited to Fukushima Prefecture to minimize the external radiation exposure level within the large areas where the radioactive materials were dispersed following the FDNPP accident (Radiation Effects Association, 2016). Many of the workers from outside the disaster-affected areas lived in hotels and dormitories and commuted daily by microbuses and shared vehicles from their quarters to the site where decontamination work was being performed (Hidaka et al., 2018). While a few of the hotels and dorms had cafeterias, most of the facilities did not, and workers were more likely to eat out or purchase a lunch box from convenience stores, leading to unhealthy and unbalanced diets.

A majority of the decontamination workers were employees of a sub-contractor, which operated a joint venture with major construction companies in decontamination work within the area designated as an Exclusion Zone due to the release of radioactivity from the stricken FDNPP (Sawano et al., 2020). The duties of decontamination workers included cutting bushes and plants, scraping up the surface soil, and packing everything into container bags for proper disposal. They typically worked an 8-hour day for 5-6 days a week (Sawano et al., 2016a).

Decontamination workers for the FDNPP accident were obliged to receive occupational safety training and radiationspecific special education, which is generally required for workers engaged in such decontamination work (Wada et al., 2012). They also received a semi-annual ionization radiation check-up and an annual general medical examination, as required by law (Suzaki and Ariyoshi, 2009; Yasui, 2013).

\section{Health risks of decontamination workers}

Several previous reports have revealed a diverse range of health risks among decontamination workers. In order to understand the totality of health risks among the decontamination workers, it is important to consider both the uniqueness of the occupational environment and the demographics of the workers, a considerable proportion of which were migrant workers from outside of the disaster-affected areas. Following the previous literature, their health risks were categorized by those associated with occupational hazards and those associated with the living environment.

\section{Health risks associated with occupational hazards}

\subsection{Radiation exposure}

Decontamination workers in areas contaminated with radiation after a nuclear disaster perform tasks such as cutting bushes and plants, scraping up surface soil, and packing radioactively contaminated materials into container bags (Yasui, 2013; Yasui, 2014; Sawano et al., 2020). Therefore, there is a risk of radiation exposure depending on the specific task. However, the risk of radiation exposure for decontamination workers in a chronic period of disaster recovery should be still far below that of workers engaged in emergency work immediately after a nuclear accident. In fact, previous surveys revealed that the workers engaged in decontamination work after the FDNPP accident were exposed to very limited radiation, as mentioned below. Radiation exposure in decontamination work can be divided into two categories: external exposure, due to ionizing radiation, and internal exposure, due to the inhalation of radioactive dust.

After the FDNPP accident, as countermeasures for external radiation exposure for decontamination workers, measurements of the ionization radiation were conducted using a dosimeter. Further, a whole-body counter was introduced for measurements of as internal radiation exposure for the 
workers. In the examination of the ionization radiation for the decontamination workers, physical examinations by physicians, laboratory examinations, eye examinations, and skin examinations were conducted (Wada et al., 2012.) .

Additionally, although the workers dealing with soil and dust, with dust concentration level exceeding $10 \mathrm{mg} / \mathrm{m}^{3}$, were required to undergo a whole-body counter examination every three months, in fact as the dust concentration measurements imposed at each decontamination site were scarce carried out, almost all decontamination workers underwent by a wholebody counter examination (Wada et al., 2012.).

The accumulated data showed that none of the workers associated with the FDNPP accident developed acute radiation syndrome, and that the external radiation exposure of the majority of the decontamination workers was very limited after the FDNPP accident; the average annual effective dose from external radiation exposure of a decontamination worker in 2015 was reported to be $0.6 \mathrm{mSv}$ (Radiation Effects Association, 2016). A previous report showed that the internal contamination among the decontamination workers by using a whole-body counter was below the detection limit for all of 83 workers who participated in the study (Tsubokura et al., 2013).

These results have clearly demonstrated that the health risks due to radiation exposure for decontamination workers are distinctly different than those for workers who responded to the accident in the immediate aftermath of the FDNPP accident (Hiraoka et al., 2015). Nevertheless, as a management for radiation exposure, the Japanese government requires employers of decontamination workers to keep records of their radiation exposure for 30 years. And thus, it is important to note that health effects beyond radiation exposure can be significant to the overall health of decontamination workers.

\subsection{Psychological problems}

Decontamination workers may experience psychological effects induced by anxiety toward radiation exposure and their work and living environment. For example, a significant increase in the rates of depression and suicide were reported among workers involved in the decontamination process after the Chernobyl accident (Rahu, 2003; Rahu et al., 2006; Rahu et al., 2014; Bromet and Luft, 2015; Laidra et al., 2015).

There is evidence of a psychological impact on the workers engaged in the decontamination after the FDNPP accident. For example, a previous report suggested that anxiety about radiation exposure among decontamination workers was indeed present and may be particularly significant among older workers, those without a contract, those without anyone to talk to, and those with comorbid conditions (Hidaka et al., 2016). Moreover, one study demonstrated that the most significant cause of anxiety among the decontamination workers was the long-term stability of their employment, while other studies suggested that anxiety may be exacerbated by living in a company dormitory or changing jobs (Hidaka et al., 2018). It has also been reported that education on the work environment management such as the handling of radiation detectors for the safety and health of decontamination workers increases anxiety about radiation exposure possibly thorough the increased radiation risk perception (Hidaka et al., 2019a, Hidaka et al., 2019b), suggesting the need to provide mental health support in addition to a proper education and training in radiation exposure for decontamination workers.

These results suggest that decontamination workers have concerns related to their working and living environments in addition to their concerns about radiation exposure. The effects specific to decontamination workers may be indistinguishable from the problems associated with workers with generally low SES and employment instability. In a meanwhile, few studies have examined whether this is linked to poorer outcomes, such as suicide, and more research is warranted in future preparedness.

\subsection{Heat stroke}

Since the accident at the FDNPP, rehabilitation work, including decontamination work, has been carried out. Decontamination work is essentially outdoor work and is affected by weather conditions such as temperature and humidity. During these tasks, heat stroke has presented as a problem for the workers and volunteers, especially during the summer period. The Ministry of Health, Labor, and Welfare issued heat stroke countermeasures, including starting work early in the morning in the summer periods and stopping work during the hottest hours of the afternoon. However, it is important for the workers themselves to be aware of the importance of heat stroke prevention because the onset of heat stroke is related to their physical condition; however, there are indications that this awareness is low, especially among the workers aged 30 years old or younger (Endo et al., 2017). In reality, there is a limit to what supervisors and companies can do to prevent heat stroke, and it is necessary to improve the education of the individual workers; however, there is limited information on what kind of education was provided to the individual decontamination workers. Decontamination work, especially in evacuation areas where equipment and medical facilities are limited, requires full preparation for heat stroke including intensive daily education, and encouraging workers to live a healthier lifestyle and to take the appropriate preventative measures.

\subsection{Trauma and bite injury}

Decontamination workers are at risk of injuries due to various factors associated with outdoor work. Typical injuries are trauma due to falls, bites from wild animals, and Hymenoptera stings. For example, in decontamination work, there is a risk of falling due to working at heights, such as on rooftops and piled-up container bags containing decontaminated waste. There are also reports of trauma from falling into ditches, hidden by overgrown vegetation in the evacuation area, as it is inaccessible and devastated (Sawano et al., 2020). Additionally, the risk of Hymenoptera stings and snakebites has been evaluated to be elevated in such areas (Ozaki et al., 2016; Ozaki et al., 2017). Surprisingly, while trauma during work is generally considered an occupational injury and the associated medical fees are supposed to be covered by the Industrial Accident Compensation Insurance, it has been reported that this is not properly administered and that for a portion of the workers, especially in low SES, these commitments are not honored (Sawano et al., 2020). In the case of critical trauma, the limited number of medical institutions capable of providing advanced medical care in the area can easily 
lead to trauma deaths that could have been prevented. Measures to prevent such events, including the proper preventive management of the occupational injury of the workers, are essential for future nuclear disaster preparedness.

\subsection{Infections}

In the living environment of the decontamination workers, specific occupational and living conditions may cause the development of infectious diseases. There have been no such reports from the Chernobyl accident or in any previous nuclear disasters. However, after the FDNPP accident, dust from the excavation of topsoil and aerosols from high-pressure washing used in decontamination has been reported to increase the risk of Legionnaires' disease (Sawano et al., 2018). Additionally, the living environments of decontamination workers, such as those living in hotels or dormitories, may contribute to the spread of various infections. As discussed below, a considerable proportion of decontamination workers have poor control of noncommunicable diseases (NCDs) such as diabetes, which can exacerbate such infections (Sawano et al., 2016a). To mitigate the risk of the spread of infectious diseases in the occupational and living environments of decontamination workers, specific provisions, including personal protective equipment such as paper masks, the disinfection of water supplies, improving the working environment such as mitigating development of dust, and educating employees, can all be effective.

\section{Health risks associated with the living environment}

\subsection{Alcohol drinking and smoking}

Previous studies have reported high rates of alcohol consumption and smoking among decontamination workers following the FDNPP accident (Sawano et al., 2016b). After the Chernobyl accident, workers engaged in clean-up work in Estonia were also reported to be significantly more susceptible to issues with alcohol (Laidra et al., 2015). This is in part due to their social and industrial background. For example, a considerable proportion of the decontamination workers were migrant workers, and their low SES partly caused this status (Sawano et al., 2016b). In addition to this background, many of the decontamination workers came from the Japanese construction industry, where the smoking rate is high (Ham et al., 2011). In recent years, it has been pointed out that the social disparity in smoking rates has been increasing in Japan (Tanaka et al., 2020). Additionally, the amount of alcohol consumed may increase as migrant workers move away from their families. Because drinking and smoking can cause the development of and exacerbate physical and mental disorders, appropriate measures should be taken to promote the health of decontamination workers after a nuclear accident, who may have mental stress toward radiation exposure.

\subsection{Obesity}

The prevalence of obesity was high among decontamination workers after the FDNPP accident (Sawano et al., 2016b). In our unpublished analysis, approximately $50 \%$ of the healthy decontamination workers were obese, while the national level of prevalence of obesity in 2018 in Japan was $32.2 \%$. As mentioned previously, many decontamination workers, especially migrant workers from outside the disaster-affected area, lived in dormitories or hotels, which may have contributed to their poor eating habits, such as eating out every day as well as the difficulty in maintaining an exercise routine (Hidaka et al., 2018). Because obesity is strongly correlated with the prevalence of NCDs such as diabetes mellitus, it is important to intervene to improve the lifestyle of workers, including their dietary habits, when large numbers of workers are recruited from areas outside of the disaster-affected regions.

\subsection{Non-communicable diseases}

After the FDNPP accident, a high prevalence of NCDs such as hypertension, dyslipidemia, and diabetes were noted among the decontamination workers, most likely related to the aforementioned obesity, alcohol consumption, smoking, and dietary issues (Sawano et al., 2016b). In contrast, for the workers engaged in post-Chernobyl decontamination process, the focus has been on the psychological effects, with very limited reports of an increased prevalence of NCDs (Rahu, 2003; Rahu et al., 2014). This fact may be attributed to the higher SES of the population, as it was primarily military personnel that were engaged in the Chernobyl accident. Additionally, the workers in the Chernobyl accident had a higher risk of radiation exposure than in the decontamination workers for the FDNPP accident. Previous studies on the FDNPP accident indicated that there may be a higher proportion of people with a low SES among the severely ill decontamination workers who required hospitalization, indicating that the health risks of the decontamination workers may be related to not only their lifestyle but also their SES (Sawano et al., 2016b). After the FDNPP accident, decontamination workers were required to undergo general medical examinations once a year in addition to semi-annual ionizing radiation examinations (Suzaki and Ariyoshi, 2009; Wada et al., 2012.).

However, the effectiveness of these examinations is in question. Because the prevalence of hypertension, dyslipidemia, and diabetes is linked to the development of more lifethreatening NCDs, such as acute coronary syndrome and strokes, more careful measures should be taken to improve the overall health of decontamination workers, including modifications to their lifestyle.

\section{Discussion}

From a review of past studies, it was determined that there is a high likelihood that decontamination workers will experience adverse health risks stemming from their working and living environments. Additionally, these two risks associated with their working and living environments can interact with each other. For example, one case report highlighted a case where a decontamination worker with poorly controlled diabetes contracted an infectious disease, possibly at work, which resulted in his eventual death (Sawano et al., 2016a). Considering such a condition that decontamination workers experience, current measure may not be sufficient for health risks arising from the working and 
living environment. Additionally, the socioeconomic vulnerability of many of the decontamination workers can lead to or exacerbate the inadequate management of their occupational safety. A previous study suggested that companies may not be properly reporting when decontamination workers suffer occupational injuries, which may prohibit their access to medical care (Sawano et al., 2020). Therefore, because the health risks to decontamination workers are due to both their working and living environments, multifaceted measures are required to comprehensively address their healthcare needs.

Interestingly, the backgrounds of the decontamination workers from the FDNPP accident and those from the Chernobyl accident are very different. First, there was no attempt at decontaminating living areas for residents return to former evacuation areas after the Chernobyl accident; the decontamination effort, focused on lifting the evacuation order after the FDNPP accident, was the first attempt of this type after a nuclear accident. Therefore, the workers involved in this work were also the first population of this type worldwide. Additionally, the risks of radiation exposure and the level of anxiety among the workers were significantly different between the Chernobyl and Fukushima accidents, reflecting the difference in the scales of the two accidents and the site of decontamination (e.g. living areas for residents after the FDNPP accident). Further, reflecting social and cultural context, many of the workers involved in the decontamination work were military personnel in the Chernobyl accident; whereas in Japan, many of the workers had socially disadvantageous backgrounds. The backgrounds of workers responding to a nuclear disaster are likely to vary depending on the sociocultural background of the country where it occurs, and thus a flexible response based on its own background should be required for better health among the decontamination workers.

In any social and cultural context, the provision of inadequate healthcare for decontamination workers not only can link to their poor prognosis such as physical disability and deaths, but can even have a negative impact on the local population in disaster-affected areas after a nuclear accident. As the healthcare resources in areas affected by a nuclear disaster are consumed, there is an increased risk of a poor prognosis if a decontamination worker develops a serious illness in these areas. Furthermore, the local population is also at risk of experiencing restricted access to healthcare if limited healthcare resources are allocated for decontamination workers. Because it is difficult to increase the available medical resources in disaster-affected areas following a nuclear disaster, both in terms of cost and logistics, the prevention of serious illnesses among decontamination workers and the promotion of their general well-being is paramount in preparing for future nuclear disasters.

\section{Conclusions}

In the decontamination work following a nuclear disaster, a large number of migrant workers may temporarily flow into disaster-affected areas because of the large volume of work. Depending on the sociocultural background of the country where the nuclear disaster occurs, people from a wide range of social classes, including those with low SES, may be involved in the work. Therefore, it is necessary to prepare for the comprehensive support of decontamination workers, which includes the effective management of diseases related to lifestyle, in addition to occupational hazards stemming from the unique work environment, such as radiation exposure, work-related infection and trauma during work, for future nuclear disaster preparedness.

\section{Conflict of interests}

Akihiko Ozaki receives personal fees from MNES Inc., outside the submitted work. Otherwise, there are no conflicts of interest related to this work.

\section{Funding}

This study is supported by research project on the health effects of radiation organized by Ministry of the Environment, Japan.

\section{References}

Anikeeva O, et al. 2016. Opportunities for general practitioners to enhance disaster preparedness among vulnerable patients. Aust. $J$. Prim. Health 22(4): 283-287.

Bethel JW, et al. 2011. Disaster preparedness among medically vulnerable populations. Am. J. Prev. Med. 40(2): 139-143.

Bromet EJ, Luft BJ. 2015. Consequences of toxic disasters for rescue, recovery, and clean-up workers require integrated mental and physical health monitoring: Editorial comment for social psychiatry and psychiatric epidemiology. Soc. Psychiatry Psychiatr. Epidemiol. 50(11): 1761-1763.

Endo S, et al. 2017. Preventive measures and lifestyle habits against exertional heat illness in radiation decontamination workers. $J$. Occup. Health 59(5): 428-432.

Ham DC, et al. 2011. Occupation and workplace policies predict smoking behaviors: analysis of national data from the current population survey. J. Occup. Environ. Med. 53(11): 1337-1345.

Hidaka T, et al. 2016. Effect of age and social connection on perceived anxiety over radiation exposure among decontamination workers in Fukushima Prefecture, Japan. J. Occup. Health 58(2): 186-195.

Hidaka T, et al. 2018. Life in company dormitories and a career change are associated with anxiety over lack of privacy among radiation decontamination workers in Fukushima Prefecture, Japan. J. Occup. Health 60(5): 361-368.

Hidaka T, et al. 2019a. Association of anxiety over radiation exposure and acquisition of knowledge regarding occupational health management in operation leader candidates of radioactivity decontamination workers in Fukushima, Japan: a cross-sectional study. Int. J. Environ. Res. Public Health 17(1).

Hidaka T, et al. 2019b. Factors associated with possession of accurate knowledge regarding occupational health management among operations leaders of radiation decontamination workers in Fukushima, Japan: a cross-sectional study. BMJ Open 9(5): e025729.

Hiraoka K, et al. 2015. Review of health issues of workers engaged in operations related to the accident at the Fukushima Daiichi Nuclear Power Plant. J. Occup. Health 57(6): 497-512.

Joyce S. 1998. Major issues in miner health. Environ. Health Perspect. 106(11): A538-A543. 
Laidra K, et al. 2015. Mental health and alcohol problems among Estonian cleanup workers 24 years after the Chernobyl accident. Soc. Psychiatry Psychiatr. Epidemiol. 50(11): 1753-1760.

Mobed K, et al. 1992. Occupational health problems among migrant and seasonal farm workers. West. J. Med. 157(3): 367-373.

Muennig P, et al. 2007. Socioeconomic status as an independent predictor of physiological biomarkers of cardiovascular disease: evidence from NHANES. Prev. Med. 45(1): 35-40.

Ohtsuru A, et al. 2015. Nuclear disasters and health: lessons learned, challenges, and proposals. Lancet 386(9992): 489-497.

Ozaki A, et al. 2016. A possible association between the resumption of agricultural activities and a venomous snakebite after Fukushima nuclear crisis. Oxf. Med. Case Rep. 2016(2): 22-23.

Ozaki A, et al. 2017. Decontamination work and the long-term increase in hospital visits for hymenoptera stings following the Fukushima nuclear disaster. Disaster Med. Public Health Prep. 11 (5): 545-551.

Radiation Effects Association. 2016. Dose distribution among workers engaged in decontamination and related works. Retrieved Oct 1, 2020, from http://www.rea.or.jp/chutou/koukai_jyosen/ H27nen/English/honbun_jyosen-h27-English.html.

Rahu M. 2003. Health effects of the Chernobyl accident: fears, rumours and the truth. Eur. J. Cancer 39(3): 295-299.

Rahu K, et al. 2006. Suicide risk among Chernobyl cleanup workers in Estonia still increased: an updated cohort study. Ann. Epidemiol. 16(12): 917-919.

Rahu K, et al. 2014. Non-cancer morbidity among Estonian Chernobyl cleanup workers: a register-based cohort study. BMJ Open 4(5): e004516.

Reid PJ, Sluis-Cremer GK. 1996. Mortality of white South African gold miners. Occup. Environ. Med. 53(1): 11-16.

Sawano T, et al. 2016a. Klebsiella pneumoniae sepsis deteriorated by uncontrolled underlying disease in a decontamination worker in Fukushima, Japan. J. Occup. Health 58(3): 320-322.

Sawano T, et al. 2016b. Non-communicable diseases in decontamination workers in areas affected by the Fukushima nuclear disaster: a retrospective observational study. BMJ Open 6(12): e013885.
Sawano T, et al. 2018. Legionnaires' disease as an occupational risk related to decontamination work after the Fukushima nuclear disaster: a case report. J. Occup. Health 60(6): 527-528.

Sawano T, et al. 2020. Concealment of trauma and occupational accidents among Fukushima nuclear disaster decontamination workers: a case report. J. Occup. Health 62(1): e12123.

Singh RB, et al. 1997. Prevalence and determinants of hypertension in the Indian social class and heart survey. J. Hum. Hypertens. 11(1): $51-56$.

Suzaki Y, Ariyoshi H. 2009. Occupational medicine in Japan. Occup. Med. (Lond.) 59(2): 133

Tanaka H, et al. 2020. Widening socioeconomic inequalities in smoking in Japan, 2001-2016. J. Epidemiol. [[UPDATE]].

Tsubokura M, et al. 2013. Measurement of internal radiation exposure among decontamination workers in villages near the crippled Fukushima Daiichi Nuclear Power Plant. Health Phys. 105(4): 379-381.

Tsubokura M, et al. 2019. Impact of decontamination on individual radiation doses from external exposure among residents of Minamisoma City after the 2011 Fukushima Daiichi nuclear power plant incident in Japan: a retrospective observational study. J. Radiol. Prot. 39(3): 854-871.

Wada K, et al. 2012. Decontamination work in the area surrounding Fukushima Dai-ichi Nuclear Power Plant: another occupational health challenge of the nuclear disaster. Arch. Environ. Occup. Health 67(3): 128-132.

World Health Organization. 2011. WHO: connecting health and labour: what role for occupational health in primary health care. In: The WHO Global Conference 29 November-1 December 2011. The Hague, The Netherlands: World Health Organization.

Yasui S. 2013. Establishment of new regulations for radiological protection for decontamination work involving radioactive fallout emitted by the Fukushima Daiichi APP accident. J. Occup. Environ. Hyg. 10(9): D119-D124.

Yasui S. 2014. New regulations for radiation protection for work involving radioactive fallout emitted by the TEPCO Fukushima Daiichi APP accident - disposal of contaminated soil and wastes. J. Occup. Environ. Hyg. 11(10): D147-D156.

Cite this article as: Sawano T, Ozaki A, Tsubokura M. 2020. Review of health risks among decontamination workers after the Fukushima Daiichi Nuclear Power Plant Accident. Radioprotection 55(4): 277-282 